\title{
Nutrition and Altitude: Strategies to Enhance Adaptation, Improve Performance and Maintain Health: A Narrative Review
}

\author{
Trent Stellingwerff ${ }^{1,2}$ (1) $\cdot$ Peter Peeling ${ }^{3,4} \cdot$ Laura A. Garvican-Lewis $^{5,6} \cdot$ Rebecca Hall $^{7}$ - Anu E. Koivisto ${ }^{8}$. \\ Ida A. Heikura ${ }^{5,6} \cdot$ Louise M. Burke ${ }^{5,6}$
}

Published online: 6 November 2019

(c) The Author(s) 2019

\begin{abstract}
Training at low to moderate altitudes $(\sim 1600-2400 \mathrm{~m})$ is a common approach used by endurance athletes to provide a distinctive environmental stressor to augment training stimulus in the anticipation of increasing subsequent altitude- and sealevel-based performance. Despite some scientific progress being made on the impact of various nutrition-related changes in physiology and associated interventions at mountaineering altitudes $(>3000 \mathrm{~m})$, the impact of nutrition and/or supplements on further optimization of these hypoxic adaptations at low-moderate altitudes is only an emerging topic. Within this narrative review we have highlighted six major themes involving nutrition: altered energy availability, iron, carbohydrate, hydration, antioxidant requirements and various performance supplements. Of these issues, emerging data suggest that particular attention be given to the potential risk for poor energy availability and increased iron requirements at the altitudes typical of elite athlete training $(\sim 1600-2400 \mathrm{~m})$ to interfere with optimal adaptations. Furthermore, the safest way to address the possible increase in oxidative stress associated with altitude exposure is via the consumption of antioxidant-rich foods rather than high-dose antioxidant supplements. Meanwhile, many other important questions regarding nutrition and altitude training remain to be answered. At the elite level of sport where the differences between winning and losing are incredibly small, the strategic use of nutritional interventions to enhance the adaptations to altitude training provides an important consideration in the search for optimal performance.
\end{abstract}

\section{Introduction}

Trent Stellingwerff

tstellingwerff@csipacific.ca

1 Canadian Sport Institute-Pacific, Institute for Sport Excellence, 4371 Interurban Road, Victoria, BC V9E 2C5, Canada

2 Department of Exercise Science, Physical and Health Education, University of Victoria, Victoria, BC, Canada

3 School of Human Sciences (Exercise and Sport Science), University of Western Australia, Crawley, Australia

4 Western Australian Institute of Sport, Mt Claremont, Australia

5 Australian Institute of Sport, Bruce, ACT, Australia

6 Mary Mackillop Institute for Health Research, Australian Catholic University, Melbourne, VIC, Australia

7 School of Health and Sports Sciences, University of the Sunshine Coast, Sippy Downs, QLD, Australia

8 Norwegian Olympic Sports Centre, Norwegian Olympic and Paralympic Committee and Confederation of Sports, Oslo, Norway
Altitude training is a common feature of elite endurance preparation and is a strategically periodized intervention in various elite athlete programs [1-4]. As extensively researched, the primary adaptive responses athletes seek during altitude sojourns include primarily the erythropoietin (EPO)-driven increase in red blood cells (or hemoglobin mass (HBmass) [1-5]). Although under-studied in elite athlete populations, there are also important non-hematological altitude adaptations, such as increased buffering capacity and potential improvements in exercise economy, as well as the extensive genetic responses of hypoxia inducible factor 1-alpha (HIF) [6]. Furthermore, recent work has also elucidated the optimal training altitudes $(\sim 1600-2400 \mathrm{~m}$ [5]) for elite athletes and theoretical timing of exposure ( 2-4 weeks) and training prior to competition [7]. [Note: all altitudes referenced below will use the thresholds defined by Bartsch and Saltin [8]: "near sea level" (0-500 m); "low altitude" (500-2000 m); "moderate altitude" (2000-3000 m); "high altitude" (3000-5500 m); and "extreme altitude" (> $5500 \mathrm{~m}$ ).] 


\section{Key Points}

While the effects of high altitude on the endocrine systems, energy intake, resting metabolic rate and body mass are severe, it appears that resting metabolic rate is also increased, albeit to a smaller extent, at low to moderate altitudes, and targeting adequate energy intake is important for optimizing health and appears to be an emerging factor associated with optimizing altitude adaptations.

Despite being iron-replete, a blunted erythropoietic response is observed in non-iron supplemented athletes during simulated altitude, with data demonstrating that most athletes will maximize the hypoxia-induced increases in hemoglobin mass while consuming $~ 100$ $200 \mathrm{mg}$ of elemental iron daily in oral form, with most evidence coming from iron salts.

There is insufficient evidence to recommend high-dose single antioxidant supplementation to attenuate altitudeinduced oxidative stress, as this may actually impair endurance and altitude-based training adaptations; although this does not seem to occur with the integration of ample amounts of antioxidant-rich foods into athletes' daily diets.

Although "nutrition at altitude" has been commonly reviewed [9-15], the vast majority of nutrition recommendations are based on research conducted at high to extreme altitudes, which do not correspond to the training altitudes typical of elite athletes ( 1600-2400 m). However, recently, several new publications on nutrition interventions at low-moderate altitudes have emerged. Within this narrative review, we have highlighted six major nutrition intervention themes to consider at low-moderate altitudes, including whether there are altered energy, iron, carbohydrate (CHO), hydration and/or antioxidant requirements, in addition to considerations for the potential use of various ergogenic aids. Figure 1 highlights these six nutrition themes, the general strength of recommendations, and gaps in knowledge (Table 1), across the various altitudes. Although there are many approaches to implementing hypoxia (see review by Millet et al. [16]), this current review will primarily focus, unless otherwise indicated, on nutrition interventions for natural terrestrial altitude training. Where possible, we will contrast our knowledge of metabolism and nutrition from high-extreme altitude research to that of low-moderate altitudes, and identify appropriate future research directions.

\section{Macronutrient and Hydration Considerations at Altitude}

Changes in macronutrient and fluid needs of athletes undertaking altitude training should be considered from two perspectives: (1) the direct effects of a hypoxic environment on physiological processes that affect metabolism, and daily utilization/loss of these nutrients; and (2) indirect effects due to a change in training load. Although the focus of this review is on the former perspective, it should be briefly observed that many athletes deliberately or inadvertently alter their typical internal and external training loads during an "altitude camp" $[4,17,18]$. Although a reduction in external training load may temporarily occur due to fatigue associated with the additional physiological stress, this may not represent a reduced internal training load, due to the augmented hypoxic stress. Furthermore, many athletes consider altitude per se, or an environment away from their home commitments, to present an opportunity for intensified training or weight loss. Although some aspects of such approaches [e.g., low energy availability (EA)] will be further discussed (and discouraged) in this review, the scientist should not neglect the importance and effects of training underpinning fuel, fluid and protein requirements, as observed with conventional sea-level training.

Most studies of the specific effects of altitude on nutrient needs have been conducted at high to extreme altitudes; these have described downregulation of protein synthesis and increased protein requirements [19] as well as changes in energy, CHO and fluid turnover [20]. Although these altitude-induced changes in metabolism have been less well studied at the typical low-moderate training altitudes, subtle effects are likely and may become amplified when they interact with high training volumes and the numerous camps and durations of altitude used by some elite athletes. Shifts towards greater $\mathrm{CHO}$ utilization have sometimes been shown at high altitudes [21], although a study in females at $4300 \mathrm{~m}$ showed decreased CHO utilization [22]. Despite high-altitude inconsistencies in changes in $\mathrm{CHO}$ oxidation, most suggest increasing dietary $\mathrm{CHO}$ requirements to replace muscle glycogen stress and a greater need/benefit of $\mathrm{CHO}$ intake during exercise $[9,13]$. However, until systematic study of these concepts during the types of training undertaken by elite athletes at low-moderate altitudes is undertaken, guidelines to address this remain speculative. Manipulating $\mathrm{CHO}$ availability according to the goal of the training sessions (e.g., training with low $\mathrm{CHO}$ availability to drive cellular adaptation and high $\mathrm{CHO}$ availability to promote performance and training intensity) is another tool available to athletes to optimize training outcomes [23]. Further investigation is needed of protocols to implement and achieve these $\mathrm{CHO}$ availability manipulations and how they might be best optimized within altitude training. 
Potential nutrition related physiological changes or nutrition interventions for various altitudes (relative level of importance / evidence for consideration compared to sea-level)

\begin{tabular}{|c|c|c|c|c|c|}
\hline Altitude & $\begin{array}{l}\text { Increased } \\
\text { glycogen use } \\
\text { / CHO needs }\end{array}$ & $\begin{array}{c}\text { Increased } \\
\text { oxidative } \\
\text { stress }\end{array}$ & $\begin{array}{l}\text { Increased } \\
\text { anti-oxidant } \\
\text { requirements }\end{array}$ & $\begin{array}{l}\text { Increased } \\
\text { iron } \\
\text { requirements }\end{array}$ & $\begin{array}{c}\text { Various } \\
\text { ergogenic } \\
\text { supplements }\end{array}$ \\
\hline $\begin{array}{l}\text { Extreme altitude } \\
(>5,500 \mathrm{~m})\end{array}$ & & & & & \\
\hline $\begin{array}{c}\text { High altitude } \\
(3,000 \text { to } 5,500 \mathrm{~m})\end{array}$ & & & & & \\
\hline $\begin{array}{l}\text { Moderate altitude } \\
\text { (2,000 to } 3,000 \mathrm{~m}\end{array}$ & & & & & \\
\hline $\begin{array}{l}\text { Low altitude } \\
\text { (500m to } 2,000 \mathrm{~m}\end{array}$ & & & $?$ & & \\
\hline
\end{tabular}

Fig. 1 Potential nutrition-related physiological/metabolic changes or nutrition interventions for various altitudes. Altitude cut-offs are as established by Bartsch and Saltin [8]. All rankings are reflective of the relative level of importance and impact, and/or evidence, compared to sea level. An equal (=) sign represents equivalent evidence and importance as at sea level. $\checkmark \checkmark \checkmark \checkmark$ is convincing evidence, $\checkmark \checkmark \checkmark$ is strong evidence, $\checkmark \checkmark$ is moderate evidence, and $\checkmark$ is low or emerg-

Hypoxia and the low air humidity associated with altitude environments are also likely to increase fluid losses at rest and during training. Local weather conditions can also vary according to the altitude location and time of the year and will also interact with altitude-specific effects. Increased respiratory water loss and the diuresis often seen in the early response to altitude exposure can create a significant increase in water requirements at the same time that reduced thirst and changes in fluid availability in a new environment may alter usual drinking practices $[2,24$, 25]. Therefore, athletes should consider altitude training a time of increased risk for dehydration and both monitor and address their hydration status appropriately [e.g., monitor urine characteristics and daily body mass (BM) changes, and be proactive with fluid intake during and after training sessions and with meals]. Taken together, whether there are consistent and performance-relevant changes in hydration and/or CHO and protein oxidation at low-moderate altitudes requires further scientific validation. At this point, we hypothesize that the individual training load via the "training camp effect" and the local altitude camp weather conditions probably influence nutritional recommendations to a greater extent than the potentially more mild hypoxic effects at low-moderate altitudes. ing evidence for a physiological/metabolic change or for nutrition intervention consideration. ? indicates emerging evidence or potentially theoretical rationale, but no published studies at specific altitude or requires more scientific confirmation. $\mathrm{BM}$ body mass, $\mathrm{CHO}$ carbohydrate, $E A$ energy availability, $E E E$ exercise energy expenditure, $E I$ energy intake

\section{Hypoxic Effects on Energy Availability, Body Mass and Altitude Adaptations}

Adequate EA is an important consideration for both sealevel and altitude training. EA reflects the amount of energy that remains after exercise for use by other body systems, including the endocrine, immune and reproductive systems, and is calculated as energy intake (EI) minus exercise energy expenditure (EEE) relative to fat-free mass (FFM) [26]. Pioneering work by Loucks and colleagues, using controlled laboratory studies, has defined low EA as $<30 \mathrm{kcal} / \mathrm{kg} \mathrm{FFM/}$ day, below which impairments to reproduction, endocrine function and bone health have been demonstrated [26]. This concept of low EA has recently been termed relative energy deficiency in sport (RED-S) and has multiple implications in both male and female athletes for iron metabolism, injury and illness, training adaptation and performance [27]. As such, optimal EA ( $45 \mathrm{kcal} / \mathrm{kg} \mathrm{FFM/day)} \mathrm{is} \mathrm{essential} \mathrm{for}$ long-term health and performance [26, 27]. However, while it is not clear whether low-moderate hypoxic exposure has additive effects on EA requirements, there are several emerging, and compelling, concepts to suggest that EA will play an important role in optimizing hypoxic adaptation.

The suppression of sex hormones (estrogen and/or testosterone) levels due to low EA may impair hematological adaptations to altitude. For example, low EA and iron 
Table 1 Equivocal data and future research directions examining the efficacy of nutrition interventions at low to moderate altitude $(\sim 1600-$ $2400 \mathrm{~m}$ ) across various nutrition themes

Altitude nutrition theme $\quad$ Equivocal data and future research directions

General macronutrient and energy requirements (e.g., EI, EEE,

Substantiate the consistency and quantity of potential altitude-induced shifts in EA, RMR or BM at low to moderate altitudes ( 1600-2400 m) [32, 38, 39]

Does long-term RED-S compromise baseline pre-altitude HBmass and/or iron values? [32]

Does RED-S compromise within altitude camp HBmass and/or other altitude-specific adaptations (injury/illness)? [30-33]

Do altitude-induced shifts in RMR and/or appetite actually impact body composition outcomes, or is this just a training camp effect? [38-41]

Do athletes naturally adjust their dietary energy and macronutrient intake while at altitude? If so, are their dietary routines at altitude in line with current recommendations?

Hydration requirements

Enhanced elucidation of actual low to moderate altitude-induced hydration requirements (especially in dry vs. moist altitude environments)

What are the actual low to moderate altitude shifts in PV, and can they be attenuated via optimal hydration interventions?

Does reduced hydration PV status, over time, potentially impact upon cardiac outputs, training quality and/or health status?

Glycogen/CHO and protein utilization changes

Are there actual shifts at low to moderate altitudes $(\sim 1600-2400 \mathrm{~m})$ towards increased CHO metabolism and protein turnover at the same relative exercise intensities as sea level?

Do athletes need to appreciably increase dietary $\mathrm{CHO}$ and/or $\mathrm{CHO}$ fueling during training sessions at low-moderate altitudes? [9-15]

Increased oxidative stress and anti-oxidant requirements

Is there an appreciable increase in RONS at low-moderate altitudes that is linked to injury/illness and/or altitude-induced adaptation?

What is the impact of single-source high-dose antioxidant supplementation on altitude-induced training adaptations?

Are there individual situations at altitude/in hypoxia where diets high in antioxidants are especially warranted to prevent illness?

What degree of oxidative stress is necessary to foster the adaptive response of altitude training, and when does oxidative stress become detrimental (e.g., increased inflammation, delayed recovery)?

Increased iron requirements

Are low baseline ferritins, with optimal hemoglobin, contraindicated for altitude training camps when iron supplementation will be optimized? [11, 54, 55]

What are the lowest iron and/or hemoglobin values that would contraindicate attending an altitude camp?

Are morning single-daily-dose iron protocols more effective than late-night single-dosing protocols at altitude as compared to alternating-day supplementation protocols? [57, 60]

Are iron salts or heme-based iron supplements most effective? Which supplements produce the least GI issues in athletes (given absence of GI issues is a prerequisite for good compliance)?

What are the iron requirements for sustained (many months) low-moderate altitude sojourns?

Will an intervention iron dose-response study (including low, moderate and high iron doses) result in significant HBmass differences and/or result in potential negative effects/downsides of excess free iron? Will it contribute to higher oxidative stress?

Various ergogenic supplements

Substantiate or refute the mechanistic and/or performance outcomes of key identified IOC supplements [107] at all altitudes (Fig. 1)

Further elucidate the adaptive hypoxic training response of buffers and/or nitrates at altitude, or whether they actually prove to attenuate altitude adaptations [120]

Further data to support or refute altitude-based supplements such as NAC or Ginkgo biloba and whether vitamins $\mathrm{B}_{6}, \mathrm{~B}_{12}$ and $\mathrm{D}$ and/or branched amino acids or glutamine impact on altitude adaptations [151, 152, 157, 159]

Investigate whether acute nitrate supplementation prior to key altitude sessions, in contrast to chronic nitrate supplementation, affects the adaptive response to altitude and performance (potentially allows higher speed/watts at key training sessions?)

Key associated references for further reading are included

$B M$ body mass, $C H O$ carbohydrate, $E A$ energy availability, $E E E$ exercise energy expenditure, $E I$ energy intake, $G I$ gastro-intestinal, $H B m a s s$ hemoglobin mass, IOC International Olympic Committee, $N A C N$-acetylcysteine, $P V$ plasma volume, $R E D$ - $S$ relative energy deficiency in sport, $R M R$ resting metabolic rate, $R O N S$ reactive oxygen and nitrogen species 
metabolism are linked [28], which may have direct effects on hematological adaptations at altitude (see Sect. 4.1). Furthermore, just $18 \mathrm{~h}$ of fasting in rats exposed to extreme altitude $(7000 \mathrm{~m})$ reduced hypoxia-induced EPO production by $85 \%$ [29]. Low EA has also been shown to drastically increase the risk of injury and illness [26, 27], which at altitude, has consistently demonstrated deleterious effects on hypoxia-induced increases in HBmass. Indeed, reductions in HBmass following altitude training have been consistently reported in ill/injured athletes [30-33] compared to the typical 3-7\% increase in HBmass in healthy counterparts [34]. Meanwhile, estrogen is important for iron homeostasis through its suppression of the peptide hormone hepcidin, which results in an increase in iron bioavailability [35]. Further, testosterone treatment in older males can reverse anemia [36]. This is supported by observed findings that amenorrheic elite female runners had an $8 \%$ lower $(p<0.05)$ baseline HBmass when compared to their eumenorrheic counterparts prior to an altitude camp [37].

\subsection{Energy Availability Considerations at Low to Moderate Altitudes}

While the effects of high-altitude exposure on endocrine systems, EI, resting metabolic rate (RMR) and ultimately $\mathrm{BM}$ are consistent and severe, the handful of research findings at low-moderate altitudes are much less consistent and appear to be far less pronounced. Indeed, emerging casestudy data include loss of appetite reported by four rowers who reported increased fatigue during a 12-day intense training block at $1800 \mathrm{~m}$ [38]. Conversely, data from five elite runners reported an increased appetite, with no change in EI, after 4 weeks of living and training at $2200 \mathrm{~m}$ [39]. However, it is important to point out that the rowers increased their training load at altitude by $113 \%$ [38], while the runners only increased their training load 37\% [39], compared to sea-level training loads. Furthermore, both negative [40, 41] as well as optimal energy balance (EB) [42] have been reported in both elite Kenyan and Ethiopian runners at moderate altitudes. Meanwhile, when 48 elite female and male distance athletes maintained moderate EA (33-36 kcal/ $\mathrm{kg}$ FFM/day, assessed over a 1-week period) across 3-4 weeks of training at $2150 \mathrm{~m}, \mathrm{BM}$ remained stable [32, 37]. However, it should be noted that dietary records [43] are poor estimates of EA when used in isolation (Table 1), and the variability of these BM and EA outcomes demonstrate that more research is required.

With respect to RMR, to our knowledge, only two studies have investigated the effects of moderate altitude on this variable in elite athletes. The first study observed five elite runners for 4 weeks at $2200 \mathrm{~m}$, reporting an increased RMR, by $19 \%$ [39]. In comparison, the second study followed four elite rowers, who reported no change in RMR after 12 days at $1800 \mathrm{~m}$ [38]. Collectively, this work presents the notion that when EA is adequate (as indicated via no change in BM in the study by Woods et al. [39]), it appears that RMR is increased at moderate altitudes similarly, albeit to a smaller extent, to high/extreme altitudes. However, given the small participant populations used here, more research is required to confirm these findings that RMR is increased at low-moderate altitudes (Table 1).

In terms of changes in BM during altitude training camps ( 3 weeks), studies report no change [32, 39, 40, $42,44]$ or minor BM decreases [38, 41, 45] when exposed to moderate altitudes. The decreases in BM may reflect low EA and have been associated with negative EB [41] and stable RMR [38]. Meanwhile, when BM was maintained (suggesting optimal EA), stable hormone concentrations [32] and increased RMR [39] were noted across an altitude camp. The importance of maintaining BM via optimal EA is highlighted by studies showing that a failure to do so may negatively influence hematological adaptations to altitude. For example, McLean et al. [33] reported that football players who lost $\geq 2 \mathrm{~kg} \mathrm{BM}$ during training at $2100 \mathrm{~m}$ only increased HBmass by $2.5 \%$ as compared to $5.0 \%$ in those who maintained BM. Furthermore, elite male cyclists significantly lost BM $(-1.2 \mathrm{~kg})$ and FFM $(-1.0 \mathrm{~kg})$ while failing to increase HBmass over a 31-day altitude camp, likely due to overtraining and/or illness [45]. Conversely, unpublished observations from four separate altitude training camps (of 3-4 weeks duration, from 2015 to 2018) with the same HBmass procedure/laboratory (Hypo2, Flagstaff, AZ, USA), featuring 114 observations, demonstrated a $-0.6 \pm 1.5 \%$ BM decrease and a $5.6 \pm 4.1 \%$ increase in HBmass, with no relationship between changes in HBmass and BM reported, and no relationship with illness (Fig. 2). However, changes in BM alone are a poor indicator of EA status, as prolonged and/or severe reductions in EI may lead to adaptive thermogenesis, which promotes maintenance or gain of BM despite low EA [46]. It is also important to note that upon arrival to altitude there is a contraction of plasma volume (PV) $[47,48]$ and typical altitude associated dehydration. Accordingly, acute small weight loss (i.e., $<2 \% \mathrm{BM}$ ) should not be confused with an actual reduced $\mathrm{EA}$, as BM alone is a poor indicator of EA. Indeed, loss of body water due to increased ventilation and diuresis is an essential short-term adaptation to altitude which serves to increase arterial oxygen content via increased hemoglobin concentration prior to longer-term erythropoietic adaptation [49]. Residual BM loss associated with PV contraction is typically reversed upon return to sea level [31]. Overall, the impact that training at moderate altitudes has on BM, EA, and subsequent endocrine and metabolic (e.g., RMR) effects warrants further investigation (Table 1). 


\section{Micronutrient Considerations to Optimize Adaptation to Altitude}

Unless there are clinical deficiencies or allergy/intolerance-dictated specific diets, athletes do not have unique, or elevated, vitamin and mineral requirements at sea level compared to the general population [50]. However, hypoxia provides a distinct environment where several micronutrients may need to be considered. This section will focus on the impact of iron status and dietary supplements, deliberating on whether anti-oxidant supplementation is warranted to minimize the production of reactive oxygen and nitrogen species (RONS) and oxidative damage at low-moderate altitudes.

\subsection{Iron and Altitude}

There are several factors that impact an athlete's HBmass response at altitude, including the hypoxic dose $(\sim+1 \%$ increase per $100 \mathrm{~h}$ at $\sim 2000 \mathrm{~m}[34,51])$ and baseline HBmass [32, 52]. Beyond this, the nutrition intervention receiving the most scientific attention with regards to optimizing adaptations to moderate altitudes is the mineral iron. In 1992, investigators such as Benjamin Levine, James Stray-Gunderson and colleagues were amongst the first to highlight that pre-existing iron deficiency (serum ferritin of $15 \pm 3$ vs. $69 \pm 10 \mu \mathrm{g} / \mathrm{l}$ ) without iron supplementation at
$2500 \mathrm{~m}$ of altitude compromised the red blood cell adaptive response to altitude training [53]. Accordingly, pre-altitude ferritin cut-offs of $<30 \mathrm{ng} / \mathrm{ml}$ and $<40 \mathrm{ng} / \mathrm{ml}$ have often been used as a pre-altitude "check" to ensure optimal adaptations and/or whether to supplement iron in females and males, respectively [11]. However, these pre-altitude ferritin cut-offs, in combination with iron supplementation, have not been scientifically validated (Table 1), although they have been utilized in a recent altitude study that showed expected HBmass increase after 3 weeks at moderate altitude $(+4.7 \%$ [44]). Furthermore, anecdotally, athletes who have low pre-altitude ferritin $(>15$ but $<30 \mathrm{ng} / \mathrm{ml})$ with normal pre-altitude hemoglobin, but who are supplemented with iron throughout an altitude camp, appear to still exhibit optimal HBmass adaptations. Indeed, several studies have shown no relationship between pre-altitude ferritin stores and the magnitude of the HBmass response $[44,54,55]$. To add to this, re-analysis of data from 49 elite athletes training at $2100 \mathrm{~m}$ while consuming 100-200 mg of elemental iron daily also supports no relationship between pre-altitude ferritin and subsequent HBmass responses, as long as athletes supplement with iron throughout the altitude camp (Pearson correlation between baseline ferritin and percentage change in HBmass $=-0.1296, p=0.38$ [32]).

Current recommendations are to assess iron status 8-10 weeks prior to altitude training [11] and to commence oral supplementation 2-3 weeks prior to altitude exposure, and to continue this supplementation throughout (Fig. 3

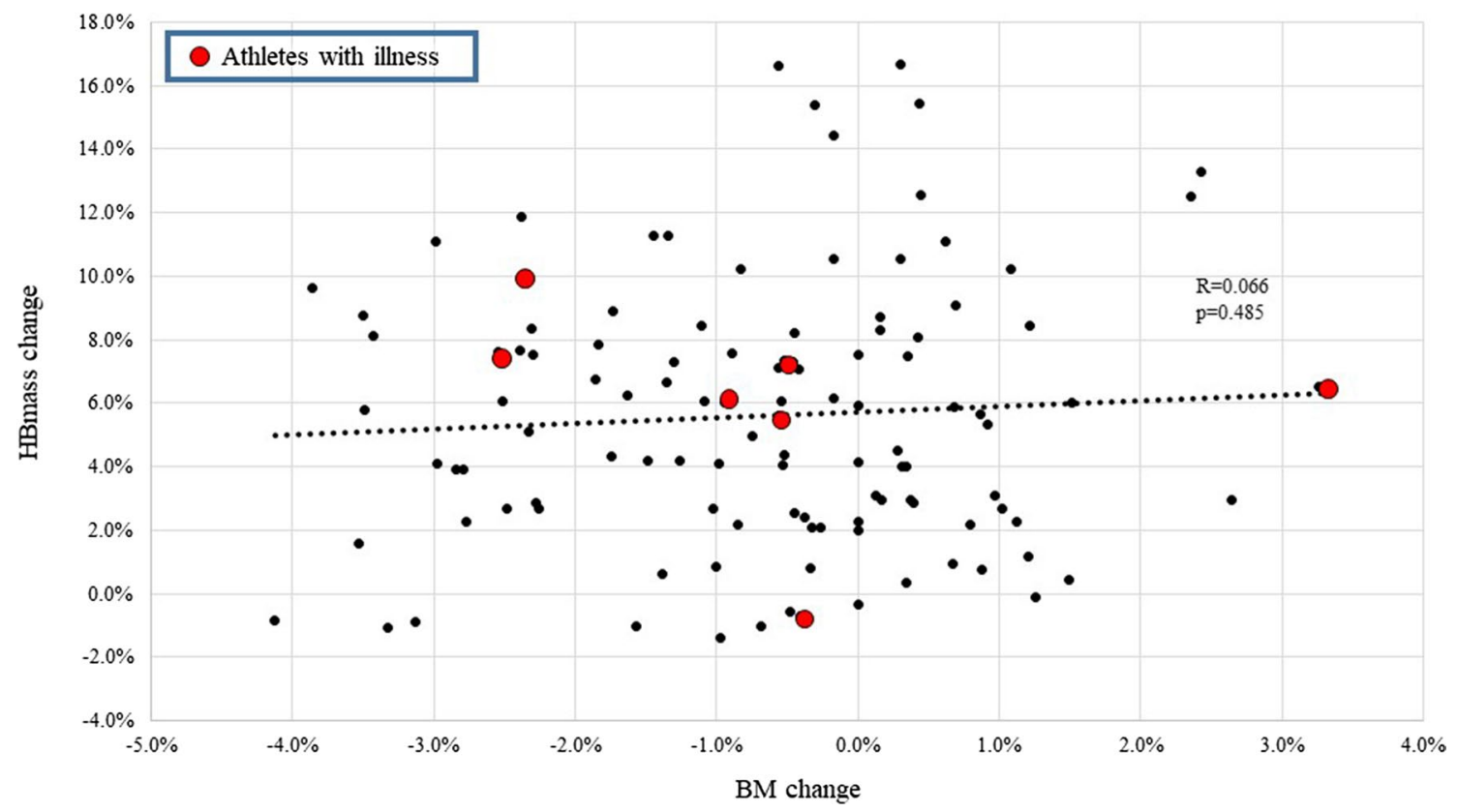

Fig. 2 The relationship between the pre- to post-altitude camp ( 3-4 weeks) percentage change in HBmass and the pre- to postaltitude camp percentage change in BM across 114 different unique athlete observations over 3-4 weeks of camp duration from 2015 to
2018 (unpublished observations). Athletes highlighted as a red dot had illness throughout the camp. The dashed line represents a linear regression $(R=0.066 ; p=0.485)$. BM body mass, HBmass hemoglobin mass 
[55-57]). However, iron stores can change appreciably in $8-10$ weeks $[58,59]$, and our current recommendation is to aim for pre-altitude blood work $\sim 4-6$ weeks prior to allow for more precise pre-altitude ferritin assessment, yet time to still supplement and correct prior to altitude if required (Fig. 3). Regarding the optimal iron dose at low-moderate altitudes, retrospective analysis of hematological data collected from athletes $(n=178)$ engaged in altitude training at moderate altitudes (1350-3000 m) demonstrated greater HBmass increases in iron-supplemented athletes versus those who were not supplemented [60]. In this study, athletes who did not supplement with iron had HBmass increases of only $1.2 \%$, while athletes who supplemented with $105 \mathrm{mg}$ or $210 \mathrm{mg}$ had HBmass increases of $3.3 \%$ and $4.0 \%$, respectively. Our altitude iron recommendations established on ferritin cut-offs of $<100, \sim 100-130$ and $>130 \mathrm{ng} / \mathrm{ml}$ (Fig. 3) are based on interpolation and/or extrapolation of existing data $[56,57,60]$. Accordingly, a blunted erythropoietic response was also observed in non-iron-supplemented athletes during simulated live-high train-low (LHTL) despite being iron replete [55]. Furthermore, altitude studies that have supplemented $\sim 200 \mathrm{mg}$ of elemental iron per day have only shown modest increases in pre- to post-ferritin levels $(\sim 5-30 \%[57,60])$, indicating the increased iron utilization at altitude and the low risk for iron overload. Nevertheless, these ferritin cut-offs require further scientific validation, as no definitive iron dose-response study at low-moderate altitudes in athletes currently exists.

Taken together, current evidence suggests that most athletes will maximize the hypoxia-induced increases in HBmass while consuming 100-200 mg of elemental iron daily in oral form, with most evidence relating to iron salts. Recent advances in intravenous (IV) iron formulations have radically changed the accessibility and safety associated with IV iron delivery [61], raising questions surrounding its suitability and efficacy as a supplementation option during altitude exposure. However, IV iron did not further augment the HBmass response to 3 weeks of simulated altitude training compared with standard oral supplementation practices (105 or $210 \mathrm{mg}$ of elemental iron/daily) in non-anemic, trained endurance athletes [55]. Thus, it would appear that oral iron supplementation remains the most appropriate option for iron-replete individuals, which better aligns with the "no needle" policies of many sporting organizations' governance processes.

The regulation of the peptide hormone hepcidin needs to be considered when looking to maximize iron bioavailability in hypoxia. Hepcidin is often referred to as the "master iron

\section{Pre-Altitude \\ $\sim 4$ to 6 weeks prior}

Baseline blood health screen

Essential:

- full blood count including $\mathrm{Hb}$ concentration and red cell indices (MCV, MCHC)

- Iron profile including, serum ferritin, soluble iron

iron saturation \& total iron binding

Consider:

- Hbmass measurement via $\mathrm{CO}$ rebreathing (independent of PV shifts)

- $\mathrm{CRP}$, as ferritin is an acute phase reactant concentration.

Aim to have blood work completed when rested (i.e. $>24 \mathrm{~h}$ after a hard workout) and healthy (no recent illness) $>24 \mathrm{~h}$ post-last iron supplement.

If ferritin $<35 \mathrm{ng} / \mathrm{mL}$.

- Consult sports physician, nutrition and/or physiology expert.

- consider starting supplemental iron immediately aiming for $100 \mathrm{mg}$ of elemental iron per day as a single daily dose $\uparrow$.

If iron deficiency is severe (ferritin $<15 \mathrm{ng} / \mathrm{mL}$ ) and/or iron deficiency anemia is suspected:

- Consult sports physician, parenteral iron (IV) may be indicated

+ Increasing Iron Bioavailability Considerations:

- Consume iron with a vitamin C source (e.g. combined iron and Vit C supplement) Menstrual cycles cause only small blood (iron) losses per month in females and norma female sex hormone levels actually decrease total hepcidin release, potentially increasing the amount of iron that can be absorbed.

- Single daily dosing protocols have been shown to minimize iron induced hepcidin release, allowing for increased bioavailability on subsequent iron intake.

\section{During-Altitude \\ $\sim 2$ weeks prior \& throughout}

If ferritin $<100 \mathrm{ng} / \mathrm{mL}$ at pre-altitude blood check and not taking iron:

- Start with $100 \mathrm{mg}$ of elemental oral iron/day for -2 weeks prior to altitude as a single daily dose $\uparrow$.

- Progress to $200 \mathrm{mg}$ of elemental iron/day in -1 week prior to altitude and continue throughout the altitude camp as a single daily doset.

- If $\mathrm{GI}$ issues present for more than 7 days, lower the dose to $100-150 \mathrm{mg}$ of elemental iron daily (or the highest dose tolerated) and contact a nutrition expert to review your supplementation strategy If ferritin is between 100 and $130 \mathrm{ng} / \mathrm{mL}$ at prealtitude blood check:

- 2 weeks prior to and throughout the altitude camp, supplement with $100 \mathrm{mg}$ elemental iron/day as a single daily dose $\uparrow$.

If ferritin $>130 \mathrm{ng} / \mathrm{mL}$ at pre-altitude blood check:

- Please contact a medical, nutrition or physiology expert for individual advice, but potentially an iron supplement may not be indicated, or only a lower daily dose (e.g. $<50 \mathrm{mg}$ of elemental iron/daily)

\section{Post-Altitude 〜several days / weeks post \\ Post blood health screen \\ Essential: \\ - full blood count including $\mathrm{Hb}$ concentration and red cell indices (MCV, MCHC) \\ - Iron profile including, serum ferritin, soluble \\ iron, iron saturation \& total iron binding Consider: \\ - Hbmass measurement via $\mathrm{CO}$ rebreathing (independent of PV shifts) \\ - CRP, as ferritin is an acute phase reactant concentration. \\ Aim to have blood work completed when rested (i.e. $>24 \mathrm{~h}$ after a hard workout) and healthy (no recent illness) $>24 \mathrm{~h}$ post-last iron supplement. \\ Adjust sea-level daily iron intake according to expert advice and post-altitude values.}

Fig. 3 Contemporary blood health screening and supplemental iron recommendations before, during and after altitude. Recommendations are based on the following references [11, 56, 57, 60, 64, 163-166] and are not to replace local and/or national sport expert advice and policies, and do not constituent medical advice. Final recommenda-
† Decreasing Iron Bioavailability Considerations:

Calcium, tannins in black tea / red wine, polyphenols in coffee, antacids, vitamin $\mathrm{E}$, tetracycline have all shown to decrease iron bioavailability to varying degrees -avoid iron intake in combination with these substances with at least a few hours of separation.

High intensity/prolonged exercise causes inflammation and the release of the hormone hepcidin, which has been shown to block iron absorption. It is best to periodize the iron supplement intake at least 4 to 6 hours after, and at least 2 hours prior to, hard exercise bouts.

Sports that involve running on hard surfaces increase foot strike hemolysis (micro-bleeding) and a greater chance of decreasing iron stores. tions should always be sought from a sports medicine physician. $C O$ carbon monoxide, $C R P$ C-reactive protein, $G I$ gastro-intestinal, $H b$ hemoglobin, HBmass hemoglobin mass, $h$ hours, $I V$ intravenous, $M C H C$ mean corpuscular hemoglobin concentration, $M C V$ mean corpuscular volume, $P V$ plasma volume, Vit vitamin 
regulator," as increased hepcidin causes a decrease in iron absorption and iron recycling within the body [62]. Hepcidin is suppressed in hypoxic conditions [57,63], but is upregulated when high amounts of iron are present in the circulation and subsequent to exercise training [64], which, in turn, reduces iron availability since both dietary iron uptake from the gut and expression of iron on macrophages are impaired [65]. Accordingly, a number of iron dosing protocols are possible, such as single or split daily doses, or dosing every other day [66, 67]. Interestingly, at sea level, multiple daily doses of iron caused an increase in hepcidin, and a decrease in the percent of iron absorbed from subsequent iron doses in iron deficient females [66], suggesting single dosing protocols may be superior. However, despite elevated hepcidin and decreased bioavailability (\% relative absorbed) with two doses per day [66], or daily iron dosing compared to alternate days [67], the total iron absorbed remains greater with a higher frequency of supplementation [notwithstanding any individual gastro-intestinal (GI) issues with greater individual doses].

Further support for a single daily iron dosing protocol comes from a recent applied study in elite runners over a training camp at $2100 \mathrm{~m}$ [57]. This study compared a split (100 mg elemental iron at 7-8 AM plus $100 \mathrm{mg}$ between 9 and $10 \mathrm{PM}$ ) versus a single (200 mg elemental iron at 9-10 PM) equivalent dose of ferrous fumarate daily for $\sim 3$ weeks. While both supplemented groups experienced a significant increase in HBmass post altitude, the singledose group had a significantly greater increase $(6.7 \pm 6.3 \%$; $p=0.048)$ compared to the split-dose group $(4.6 \pm 3.9 \%)$. The trade-off may be greater reports of GI concerns with the single dose, as there was a $37 \%$ increase in the overall GI distress score associated with the single versus split dose over the first 2 weeks. However, this difference was not apparent by week 3 , suggesting gut adaptation can occur to the greater single dose [57]. Also, there may be different GI tolerance to different types of oral iron supplements [68], which also may be individually trialed. Of note, the efficacy of an alternate-day iron supplementation protocol is yet to be explored in athletes at altitude, but offers a promising possible avenue for further research (Table 1).

In conclusion, since no correlation has been observed between pre-altitude ferritin stores and the magnitude of the erythropoietic/HBmass response [32, 54, 55], it appears that iron availability via supplementation during altitude is more important for optimal adaptations than pre-altitude iron stores [56, 57]. Nevertheless, optimizing iron bioavailability, via optimal iron dose timing, requires an appreciation of the temporal effects of hepcidin that are influenced by baseline ferritin [64], timing of multiple daily iron doses [66, 67], timing, duration and intensity of training [64], and diurnal effects [69]. Figure 3 highlights our current knowledge and recommendations regarding blood health screening and supplemental iron recommendations before, during and after altitude, including highlighting factors that will increase or decrease oral iron bioavailability. We recommend the involvement of a sports medicine physician in this process, as excess iron supplementation and clinically elevated endogenous iron stores can have negative health consequences [70, 71].

\subsection{Antioxidant Considerations}

Exercise at moderate altitudes is associated with increased production of RONS with reduced antioxidant capacity, leading to oxidative stress $[72,73]$. The excessive overproduction of RONS, in excess of the endogenous antioxidant defense systems, can cause damage to lipids, proteins and DNA which may impair cell and immune function, resulting in delayed post-exercise recovery [74]. Both acute [75, $76]$ and chronic exposure to hypoxia [72, 77, 78] augments oxidative stress in well-trained athletes, while reduced antioxidant capacity may persist for up to 2 weeks following altitude training [79]. Interestingly, normobaric hypoxia appears to produce a larger increase in oxidative stress than hypobaric hypoxia [80], while a recent study in a team sport setting showed no impact of intermittent hypoxia on biomarkers of oxidative stress [81]. Although several factors can modulate the oxidative stress response to altitude (e.g., the intensity and type of training [82]), it can be generalized that a greater level of hypoxic stimulus results in greater oxidative stress (Fig. $1[83,84]$ ). The clinical implications of altitude-induced oxidative stress are not entirely clear [85, 86], beyond being linked to acute mountain sickness (AMS) at high altitudes [87, 88]. At moderate altitudes, some studies have shown increased inflammation and illness in association with higher levels of oxidative stress $[89,90]$, but others have not [81]. It is important to note that, although there is some evidence of immunological biomarker disturbances at low-moderate altitudes in elite athletes [91, 92] and anecdotally there is an assumption of increased rate of illness at altitude, there is actually limited evidence of an increased rate of illness at low-moderate altitudes. In fact, a recent athlete and immune function review by Walsh et al. [93] highlights that there is no evidence that exercising in extreme environments poses any additional immune threat, and some recent evidence suggests that immune health may actually be enhanced by regular intermittent environmental stressors.

Given that exogenous antioxidants neutralize free radicals, it is logical to hypothesize that antioxidant supplementation would be a worthy intervention to combat altitudeinduced oxidative stress and its potentially associated perils. Although early investigations have shown that antioxidant supplements had modulating effects on oxidative stress and AMS symptoms at high altitudes [94, 95], more recent 
studies indicate no effect [96-98] or mixed results [99]. Importantly, the majority of the studies have been conducted in military training settings and/or at altitudes $>4000 \mathrm{~m}$, and thus, do not reflect the contemporary altitude training regimes of athletes. Furthermore, none of these studies have assessed the impact of antioxidant supplementation on training adaptation. With the current understanding of the essential role of RONS in initiating the positive adaptive response to endurance training [100], hypoxia [101] and upregulation of the endogenous antioxidant defenses [102], dampening RONS with antioxidants might actually be counterproductive and reduce the adaptive responses to altitude training (Table 1), which has been shown at sea level [103-105]. Two recent studies have examined the effect of antioxidants from food sources on the adaptive response to altitude training [44], and oxidative stress and inflammation [106]. The first study [44] revealed that more than doubling the daily intake of antioxidant-rich foods during a 3-week altitude camp $(2320 \mathrm{~m})$ did not interfere with the training responses in elite endurance athletes [measured as HBmass and maximum rate of oxygen consumption $\left.\left(V \mathrm{O}_{2 \max }\right)\right]$. While the follow-up study showed that the food-based antioxidant intervention elevated plasma antioxidant capacity and attenuated some of the altitude-induced increases in systemic inflammatory biomarkers, it had no impact on altitude-induced oxidative stress in the elite athlete population [106].

Collectively, there is not sufficient evidence to recommend high-dose single antioxidant supplementation to attenuate altitude-induced oxidative stress, especially at low-moderate altitudes. Furthermore, the impact of antioxidant supplements on the adaptive training response to altitude requires further research (Table 1). At present, integrating ample amounts of antioxidant-rich foods into athletes' daily dietary regimes while training at altitude seems the most reasonable advice, including a vitamin $\mathrm{C}$ source (e.g., orange juice, low-dose vitamin $\mathrm{C}$ supplement) with the athletes' iron supplement to optimize bioavailability (Fig. 3).

\section{Ergogenic Supplement Considerations During Altitude}

Despite a growing body of evidence for a handful of specific ergogenic aids for performance enhancement at sea level [107], there are very few acute or chronic supplementation studies completed in hypoxic conditions. Given that hypoxia changes oxygen extraction, delivery and uptake, as well as altering lactate kinetics and buffering, we would caution against the indiscriminate use of sea-level ergogenic aids until more hypoxia-based data are generated. Nevertheless, there are some preliminary data on nitrate supplementation and some theoretical use of buffers at altitude, along with several other emerging supplements that will be covered in this section.

\subsection{Nitrates/Beetroot at Altitude}

Nitric oxide (NO) is a pleiotropic signaling molecule and a regulator of many physiological and adaptive processes that are endogenously stimulated by hypoxia. Therefore, dietary nitrate $\left(\mathrm{NO}_{3}\right.$; an $\mathrm{NO}$ precursor) supplementation, usually in the form of concentrated beetroot consumption, during hypoxia has garnered much recent attention [108, 109]. Accordingly, one might hypothesize even greater effects of $\mathrm{NO}_{3}^{-}$supplementation at altitude. Similar to the data found in normoxia, there are several studies confirming enhanced exercise economy (reduced steady-state $V \mathrm{O}_{2}$ ), by $\sim 5-10 \%$, in hypoxia and/or enhanced performance outcomes in recreationally active subjects after $\mathrm{NO}_{3}{ }^{-}$supplementation [110-112]. However, also similar to the normoxic literature, four recent hypoxia-based studies have failed to show these outcomes in elite endurance trained subjects $\left(V \mathrm{O}_{2 \max }\right.$ $>60 \mathrm{ml} / \mathrm{kg} / \mathrm{min}$ ); although some individuals appeared to benefit [113-117], this is not always the case [118]. Therefore, similar to the normoxic data, the majority of studies in elite endurance-trained subjects show no further benefits of $\mathrm{NO}_{3}{ }^{-}$supplementation in hypoxia.

Perhaps not surprisingly, given that $\mathrm{NO}_{3}{ }^{-}$supplementation increases $\mathrm{O}_{2}$ delivery, in both recreational [111, 112] and elite [116] subjects, $\mathrm{NO}_{3}{ }^{-}$supplementation has resulted in a small 1-4\% increase in arterial $\mathrm{O}_{2}$ saturation $\left(\mathrm{S}_{\mathrm{a}} \mathrm{O}_{2}\right)$ via pulse oximetry during hypoxic exercise (thus less desaturation). However, given the links between decreases in $\mathrm{S}_{\mathrm{a}} \mathrm{O}_{2}$ and EPO release [119] and HIF-1-alpha responses, one might question whether chronic $\mathrm{NO}_{3}{ }^{-}$supplementation while training at altitude might actually attenuate some of the hypoxia-induced adaptations. Indeed, several studies have shown no performance enhancing or training adaptation effect of chronic $\mathrm{NO}_{3}{ }^{-}$supplementation during hypoxic training over 5-6 weeks [120,121], suggesting that chronic $\mathrm{NO}_{3}{ }^{-}$intake might attenuate training adaptations by decreasing the drop in arterial $\left(\mathrm{S}_{\mathrm{a}} \mathrm{O}_{2}\right)$ and muscle $\mathrm{O}_{2}$ saturationsfactors that serve as "signals" for hypoxic adaptations [120]. Taken together, given the lack of consistent data and/or several studies suggesting contraindications [120, 122], we cannot conclusively recommend $\mathrm{NO}_{3}{ }^{-}$supplementation during altitude training in elite athletes unless individual outcomes have been quantified.

\subsection{Hypoxic Acid/Base Regulation and Exogenous Buffering Considerations}

During progressively intense exercise, the drop in muscular $\mathrm{pH}$ via hydrogen ion $\left(\mathrm{H}^{+}\right)$production, which is exacerbated by hypoxia at the same absolute workloads, has been 
shown to negatively affect metabolic processes, such as the inhibition of glycolysis and muscle contraction processes, ultimately resulting in fatigue and decreased performance [123]. Therefore, the enhancement of both intra- (inside) and extra-muscular (outside) buffering of $\mathrm{H}^{+}$should lead to an increase in performance where metabolic acidosis is a limiting factor. Accordingly, humans have evolved to have many varying endogenous mechanisms contributing to total buffering capacity, which are innately enhanced upon ascent to altitude [6] and potentially increased by several nutritionbased ergogenic aids. These ergogenic aids with significant sea-level evidence [107] include (1) $\beta$-alanine (BA) supplementation leading to intra-cellular muscle carnosine synthesis (3-6 g BA/daily for 6-8 weeks) and (2) sodium bicarbonate $\left(\mathrm{NaHCO}_{3}\right)$ or citrate supplementation leading to extra-cellular increases in bicarbonate $\left(\mathrm{HCO}_{3}^{-}\right)$[acutely, $\sim 300 \mathrm{mg} \mathrm{NaHCO} / 3 / \mathrm{kg} \mathrm{BM}$ taken $1-2 \mathrm{~h}$ prior to competition]. It is beyond the scope of this review to unravel the complexities of anaerobic performance determinants and associated potential ergogenic aids (for recent reviews, see Peeling et al. [107] and Stellingwerff et al. [124, 125], as well as the extensive literature on acid-base regulation during exercise [123] and/or during hypoxia [126]). Instead, this section will briefly overview the buffering changes upon ascent to altitude and then examine the scant data on whether exogenous buffering supplements should be considered at altitude (Fig. 1).

Upon immediate ascent to altitude, there is a very rapid hyperventilatory response to hypoxia to raise $\mathrm{PO}_{2}$, which leads to respiratory alkalosis, resulting in decreased $\mathrm{H}^{+}$, increased $\mathrm{pH}$ and increased renal $\mathrm{HCO}_{3}{ }^{-}$excretion, resulting in decreased blood $\mathrm{HCO}_{3}{ }^{-}$; for reviews see Gore et al. [6] and Cerretelli and Samaja [126]. Subsequent to this immediate response, chronic altitude (days to weeks) actually increases intra- and extra-cellular buffering capacity [127-129]. Indeed, hypoxia-induced changes in blood $\mathrm{pH}$ can occur in elite 400-m runners in just several days [130]. In fact, enhancement of critical buffering transporters in blood erythrocytes (via increased monocarboxylate and bicarbonate $\left(\mathrm{Cl}^{-} / \mathrm{HCO}_{3}{ }^{-}\right)$transporters [127]) and a 5-6\% increase in muscle buffering $[128,129]$ have both been shown in just 2 weeks of hypoxia. Therefore, given the drop in blood $\mathrm{HCO}_{3}{ }^{-}$, one might hypothesize that exogenous $\mathrm{NaHCO}_{3}$ or citrate supplementation may actually be more advantageous for performance in hypoxia. However, in the handful of studies that have used $\mathrm{NaHCO}_{3}$ or citrate in hypoxic conditions, six studies have shown no ergogenic effect [131-136], while one study has shown an increase in the anaerobic $\left(W^{\prime}\right)$ component, which would be suggestive of a performance enhancement, at simulated altitude $\left(14.5 \% \mathrm{O}_{2} ; \sim 2800 \mathrm{~m}\right.$ [137]). Regardless, it is difficult to compare any of these studies, because of different levels of hypoxia, performance protocols and states of hypoxic adaptation, as well as several of the studies being potentially under-powered to detect a performance difference $(n \leq 7$ [131, 134, 135]). Obviously, much more research is required to better understand the limiting effects of performance in hypoxia, the time course and impact of these extracellular buffering changes in elite athletes at low-moderate altitudes, as well as the mechanism(s) responsible for the subsequent enhanced muscle buffering capacity (Table 1).

The chronic utilization of nutritional buffers to potentially enhance training adaptations is not well understood. For example, there are only a few studies examining the chronic effect of $\mathrm{NaHCO}_{3}$ supplementation (5-7 days) in normoxia, all of which have initially demonstrated promising outcomes [138-141]. However, some individuals will suffer from GI upset and/or increased fluid retention and BM increases $(+1-3 \% \mathrm{BM})$ due to the high sodium ingestion [142, 143] following $\mathrm{NaHCO}_{3}{ }^{-}$supplementation, potentially negating the performance outcomes [144-146]. All of these negative side effects may be exacerbated with prolonged chronic $\mathrm{NaHCO}_{3}{ }^{-}$protocols. Additionally, two studies have examined whether augmented carnosine via BA supplementation may lead to an enhanced training effect, with one study showing a trend for greater resistance-training volume [147] and another finding no influence of BA to further enhance high-intensity interval training [148]. We are unaware of any prolonged chronic $\mathrm{NaHCO}_{3}$ supplementation studies conducted at altitude/hypoxia. Conversely, we are only aware of a single study examining the acute effects of $\mathrm{NaHCO}_{3}$ supplementation both prior to and after 5 weeks of BA supplementation. All of these trials were conducted in simulated hypoxia $\left(15.5 \% \mathrm{O}_{2}=\sim 2400 \mathrm{~m}\right)$, in which neither BA nor $\mathrm{NaHCO}_{3}$ caused any performance benefits [149]. Obviously, our global understanding of the adaptive effects of buffers is not well understood at either sea level or altitude (Table 1).

Taken together, current evidence would not support the use of exogenous $\mathrm{NaHCO}_{3}$ or citrate supplementation to augment acute hypoxic performance. Furthermore, given the remaining questions around the innate magnitude and timing of acid-base/buffering changes in elite athletes at low-moderate altitudes, let alone the potential adaptive impact of chronic exogenous buffers, we also cannot conclusively recommend the chronic use of $\mathrm{NaHCO}_{3}$ or citrate supplementation. However, due to BA's long supplementation period ( $~ 6-8$ weeks) to augment muscle carnosine, one might consider its utilization if the timing were critical for post-altitude competitions, with no current anecdotal evidence to report any apparent negative side effects (unpublished observations).

\subsection{Other Potential Supplements: $N$-Acetylcysteine and Ginkgo biloba}

Limited evidence exists for alternative nutritional supplements that have extensive data as potential ergogenic aids 
for enhancing adaptation to altitude. For example, we are unaware of any intervention studies investigating the impact of vitamins $\mathrm{B}_{6}, \mathrm{~B}_{12}$ and $\mathrm{D}$ or glutamine or branched chain amino acids in athletes at low-moderate altitudes. Therefore, whether a higher intake of these vitamins and proteins (in the form of supplements) would have additional benefits has not been investigated and again highlights areas for future research. However, when looking beyond the aforementioned prospects of nitrate and buffers, the thiolcontaining compound $N$-acetylcysteine (NAC) seems to show mechanistic promise. Previous work has shown that NAC increases circulating free cysteine levels, which, in the presence of increased glutathione demand, can support glutathione synthesis and prevent its depletion [150]. Interactions between NAC, cysteine and glutathione are suggested to act in potentially numerous mechanistic ways that may be beneficial for athlete performance, recovery and adaptation. For instance, NAC ingestion is proposed to result in an anti-oxidant effect that minimizes the oxidative stress and inflammatory response imposed from physical activity [151] (see Sect. 4.2). Furthermore, NAC is proposed to enhance fatigue resistance [152] and improve athletic performance [151]; to enhance immune system function [153], hemodynamics and muscle blood flow [154]; and to modulate EPO production and the hypoxic ventilatory response [155]. Intuitively, each of these mechanisms appears likely to support a positive adaptation to hypoxic environments such as altitude exposure. However, scant literature exists to explore such a prospect in applied athlete settings where an altitude sojourn has occurred. Regardless, the previous literature showing a positive impact of NAC supplementation on these relevant physiological outcomes has generally provided the thiol compound in oral dosages ranging from 600-1200 mg/day for a 5- to 9-day period [151, 154, 155]. However, it should be noted that not all literature supports the positive modulation of NAC on EPO production [156], and when consumed in high doses for prolonged periods of time (i.e., $1200 \mathrm{mg} /$ day for 4 weeks, followed by $2400 \mathrm{mg} /$ day for a further 2 weeks), pro-oxidant, rather than anti-oxidant, effects have been reported [157], which may actually serve to attenuate aerobic adaptations (see Sect. 4.2). With this in mind, further research is clearly required before NAC can be recommended as a useful supplement for use prior to and/or throughout altitude exposure in athletes, with factors such as dose, duration of consumption and the resultant potential for mechanistic promise to convert to enhanced adaptation all needing further clarification.

Any indirect benefits of a supplement that might support an athlete's immune function are of key interest, since it is well-documented that unaccustomed altitude exposure places an additional burden on the immune system [158]. Maintaining an athlete's immune function and/or reducing the impact of any altitude-induced illness while under such environmental stress may lead to enhanced overall adaptations. With this in mind, there appears to be potential for the use of the herb extract G. biloba (GBE), with proposed mechanisms such as reducing tissue hypoxia, increasing vasodilation and, via its anti-oxidant properties, possibly reducing the incidence of a mild AMS [159], characterized by headache, lightheadedness, fatigue, nausea, and insomnia [160]. Such effects can negatively impact on an athlete's ability to train, and therefore, their overall adaptation to an altitude exposure may be compromised [161]. Although a promising prospect, recent meta-analyses of GBE shows equivocal outcomes of its impact on AMS prevention (only $57 \%$ of included studies showed a positive outcome [159]). Investigations exploring the potential prophylactic nature of GBE have used daily split doses of 80-120 mg, consumed over a 3- to 5-day period both before and/or during the altitude sojourn [160, 162]; however, it should be considered that the majority of these studies have focused on trekkers at high to extreme altitudes, rather than athlete populations at low-moderate altitudes. Therefore, similar to NAC supplementation, more research is needed before confident recommendations on GBE supplementation for reductions in altitude-induced illness and/or AMS symptoms can be made.

\section{Future Directions and Conclusions}

Even though the hypoxic stress of altitudes $<2400$ m may seem very minor in comparison with mountaineering altitudes, the extreme training intensities and volumes of elite athletes can be compounded and need to be considered. For example, elite endurance athletes may spend as much as $20-25 \%$ of the entire year at altitude through the implementation of many camps $[1,4]$. Therefore, despite the fact that RMR might be only increased $\sim 300 \mathrm{kcal} /$ day at $\sim 2000 \mathrm{~m}$ [39] (see Sect. 3), if an athlete spends 3-4 months at altitude, this actually amounts to a $\sim 25,000$ kcal yearly mismatch. Indeed, future altitude studies need to make compelling efforts to quantify both EA and actual training loads to better elucidate whether training camp outcomes are actually due to the hypoxic stress and not due to altered training and/ or EA. Within this narrative review, we have focused on six key altitude-related nutrition themes (Fig. 1), and a repeated thesis is the relative lack of data at the low-moderate altitudes $(\sim 1600-2400 \mathrm{~m})$ that elite athletes typical utilize for optimal training adaptations [5]. Accordingly, many research questions have been raised (Table 1), with a definitive iron dose-response study at natural altitudes in athletes probably being one of the key current gaps in the literature. In conclusion, given the infinitesimal difference between winning and losing, coupled with the fact that most elite endurance athletes/programs utilize altitude to some degree as part of their preparation, the optimization of nutritional interventions to 
optimize altitude adaptations is an ever-important performance aspect needing consideration.

Acknowledgements This supplement is supported by the Gatorade Sports Science Institute (GSSI). The supplement was guest edited by Lawrence L. Spriet, who attended a meeting of the GSSI Expert Panel in March 2019 and received honoraria from the GSSI, a division of PepsiCo, Inc., for his participation in the meeting. Dr Spriet received no honoraria for guest editing the supplement. Dr Spriet suggested peer reviewers for each paper, which were sent to the Sports Medicine Editor-in-Chief for approval, prior to any reviewers being approached. Dr Spriet provided comments on each paper and made an editorial decision based on comments from the peer reviewers and the Editorin-Chief. Where decisions were uncertain, Dr Spriet consulted with the Editor-in-Chief.

\section{Compliance with Ethical Standards}

Funding This article is based on a presentation by Trent Stellingwerff to the GSSI Expert Panel in March 2019. Funding for attendance at that meeting together with an honorarium for preparation of this article were provided by the GSSI. No other sources of funding were used to assist in the preparation of this article.

Conflict of interest Trent Stellingwerff, Peter Peeling, Laura GarvicanLewis, Rebecca Hall, Anu Koivisto, Ida Heikura and Louise Burke have no conflicts of interest relevant to the content of this article.

Open Access This article is distributed under the terms of the Creative Commons Attribution 4.0 International License (http://creativeco mmons.org/licenses/by/4.0/), which permits unrestricted use, distribution, and reproduction in any medium, provided you give appropriate credit to the original author(s) and the source, provide a link to the Creative Commons license, and indicate if changes were made.

\section{References}

1. Mujika I, Sharma AP, Stellingwerff T. Contemporary periodization of altitude training for elite endurance athletes: a narrative review. Sports Med. 2019;49(11):1651-69. https://doi. org/10.1007/s40279-019-01165-y.

2. Wilber RL. Altitude training and athletic performance. Champaign: Human Kinetics; 2007.

3. Bonetti DL, Hopkins WG. Sea-level exercise performance following adaptation to hypoxia: a meta-analysis. Sports Med. 2009;39(2):107-27.

4. Saunders PU, Pyne DB, Gore CJ. Endurance training at altitude. High Alt Med Biol. 2009;10(2):135-48.

5. Chapman RF, Karlsen T, Resaland GK, et al. Defining the "dose" of altitude training: how high to live for optimal sea level performance enhancement. J Appl Physiol. 2014;116(6):595-603.

6. Gore CJ, Clark SA, Saunders PU. Nonhematological mechanisms of improved sea-level performance after hypoxic exposure. Med Sci Sports Exerc. 2007;39(9):1600-9.

7. Chapman RF, Laymon Stickford AS, Lundby C, et al. Timing of return from altitude training for optimal sea level performance. J Appl Physiol. 2014;116(7):837-43.

8. Bartsch P, Saltin B. General introduction to altitude adaptation and mountain sickness. Scand J Med Sci Sports. 2008;18(Suppl 1):1-10.
9. Stellingwerff T, Pyne DB, Burke LM. Nutrition considerations in special environments for aquatic sports. Int J Sport Nutr Exerc Metab. 2014;24(4):470-9.

10. Meyer NL, Manore MM, Helle C. Nutrition for winter sports. J Sports Sci. 2011;29(Suppl 1):S127-36.

11. Bergeron MF, Bahr R, Bartsch P, et al. International Olympic Committee consensus statement on thermoregulatory and altitude challenges for high-level athletes. Br J Sports Med. 2012;46(11):770-9.

12. Hawley JA, Gibala MJ, Bermon S. Innovations in athletic preparation: role of substrate availability to modify training adaptation and performance. J Sports Sci. 2007;25(Suppl 1):S115-24.

13. Michalczyk M, Czuba M, Zydek G, et al. Dietary recommendations for cyclists during altitude training. Nutrients. 2016;8(6):E377.

14. Wing-Gaia SL. Nutritional strategies for the preservation of fat free mass at high altitude. Nutrients. 2014;6(2):665-81.

15. Hamad N, Travis SP. Weight loss at high altitude: pathophysiology and practical implications. Eur J Gastroenterol Hepatol. 2006;18(1):5-10.

16. Millet GP, Roels B, Schmitt L, et al. Combining hypoxic methods for peak performance. Sports Med. 2010;40(1):1-25.

17. Sharma AP, Saunders PU, Garvican-Lewis LA, et al. Training quantification and periodization during live high train high at $2100 \mathrm{M}$ in elite runners: an observational cohort case study. J Sports Sci Med. 2018;17(4):607-16.

18. Sharma AP, Saunders PU, Garvican-Lewis LA, et al. Normobaric hypoxia reduces $\mathrm{VO}_{2}$ at different intensities in highly trained runners. Med Sci Sports Exerc. 2019;51(1):174-82.

19. Pasiakos SM, Berryman CE, Carrigan CT, et al. Muscle protein turnover and the molecular regulation of muscle mass during hypoxia. Med Sci Sports Exerc. 2017;49(7):1340-50.

20. Butterfield GE. Nutrient requirements at high altitude. Clin Sports Med, viii. 1999;18(3):607-21, viii.

21. Brooks GA, Butterfield GE, Wolfe RR, et al. Increased dependence on blood glucose after acclimatization to 4,300 m. J Appl Physiol. 1991;70(2):919-27.

22. Braun B, Mawson JT, Muza SR, et al. Women at altitude: carbohydrate utilization during exercise at 4,300 m. J Appl Physiol. 2000;88(1):246-56.

23. Burke LM, Hawley JA, Jeukendrup A, et al. Toward a common understanding of diet-exercise strategies to manipulate fuel availability for training and competition preparation in endurance sport. Int J Sport Nutr Exerc Metab. 2018;28(5):451-63.

24. Butterfield GE, Gates J, Fleming S, et al. Increased energy intake minimizes weight loss in men at high altitude. J Appl Physiol. 1992;72(5):1741-8.

25. Mawson JT, Braun B, Rock PB, et al. Women at altitude: energy requirement at 4,300 m. J Appl Physiol. 2000;88(1):272-81.

26. Loucks AB, Kiens B, Wright HH. Energy availability in athletes. J Sports Sci. 2011;29(Suppl 1):S7-15.

27. Mountjoy M, Sundgot-Borgen J, Burke L, et al. International Olympic Committee (IOC) consensus statement on relative energy deficiency in sport (RED-S): 2018 update. Int J Sport Nutr Exerc Metab. 2018;28(4):316-31.

28. Petkus DL, Murray-Kolb LE, De Souza MJ. The unexplored crossroads of the female athlete triad and iron deficiency: a narrative review. Sports Med. 2017;47(9):1721-37.

29. Jelkmann W, Kurtz A, Bauer C. Effects of fasting on the hypoxiainduced erythropoietin production in rats. Pflugers Arch. 1983;396(2):174-5.

30. Gough CE, Sharpe K, Garvican LA, et al. The effects of injury and illness on haemoglobin mass. Int J Sports Med. 2013;34(9):763-9. 
31. Wachsmuth NB, Volzke C, Prommer N, et al. The effects of classic altitude training on hemoglobin mass in swimmers. Eur $\mathbf{J}$ Appl Physiol. 2013;113(5):1199-211.

32. Heikura IA, Burke LM, Bergland D, et al. Impact of energy availability, health, and sex on hemoglobin-mass responses following live-high-train-high altitude training in elite female and male distance athletes. Int J Sports Physiol Perform. 2018;13(8):1090-6.

33. McLean BD, Buttifant D, Gore CJ, et al. Year-to-year variability in haemoglobin mass response to two altitude training camps. $\mathrm{Br}$ J Sports Med. 2013;47(Suppl 1):i51-8.

34. Garvican-Lewis LA, Sharpe K, Gore CJ. Time for a new metric for hypoxic dose? J Appl Physiol. 2016;121(1):352-5.

35. Hou Y, Zhang S, Wang L, et al. Estrogen regulates iron homeostasis through governing hepatic hepcidin expression via an estrogen response element. Gene. 2012;511(2):398-403.

36. Roy CN, Snyder PJ, Stephens-Shields AJ, et al. Association of testosterone levels with anemia in older men: a controlled clinical trial. JAMA Intern Med. 2017;177(4):480-90.

37. Heikura IA, Uusitalo ALT, Stellingwerff T, et al. Low energy availability is difficult to assess but outcomes have large impact on bone injury rates in elite distance athletes. Int J Sport Nutr Exerc Metab. 2018;28(4):403-11.

38. Woods AL, Garvican-Lewis LA, Rice A, et al. 12 days of altitude exposure at $1800 \mathrm{~m}$ does not increase resting metabolic rate in elite rowers. Appl Physiol Nutr Metab. 2017;42(6):672-6.

39. Woods AL, Sharma AP, Garvican-Lewis LA, et al. Four weeks of classical altitude training increases resting metabolic rate in highly trained middle-distance runners. Int J Sport Nutr Exerc Metab. 2017;27(1):83-90.

40. Fudge BW, Westerterp KR, Kiplamai FK, et al. Evidence of negative energy balance using doubly labelled water in elite Kenyan endurance runners prior to competition. Br J Nutr. 2006;95(1):59-66.

41. Onywera VO, Kiplamai FK, Boit MK, et al. Food and macronutrient intake of elite kenyan distance runners. Int J Sport Nutr Exerc Metab. 2004;14(6):709-19.

42. Beis LY, Willkomm L, Ross R, et al. Food and macronutrient intake of elite Ethiopian distance runners. J Int Soc Sports Nutr. 2011;8:7.

43. Burke LM, Lundy B, Fahrenholtz IL, et al. Pitfalls of conducting and interpreting estimates of energy availability in free-living athletes. Int J Sport Nutr Exerc Metab. 2018;28(4):350-63.

44. Koivisto AE, Paulsen G, Paur I, et al. Antioxidant-rich foods and response to altitude training: a randomized controlled trial in elite endurance athletes. Scand J Med Sci Sports. 2018;28(9):1982-95.

45. Gore CJ, Hahn A, Rice A, et al. Altitude training at $2690 \mathrm{~m}$ does not increase total haemoglobin mass or sea level $V \mathrm{O}_{2 \max }$ in world champion track cyclists. J Sci Med Sport. 1998;1(3):156-70.

46. Trexler ET, Smith-Ryan AE, Norton LE. Metabolic adaptation to weight loss: implications for the athlete. J Int Soc Sports Nutr. 2014;11(1):7.

47. Siebenmann C, Cathomen A, Hug M, et al. Hemoglobin mass and intravascular volume kinetics during and after exposure to 3,454-m altitude. J Appl Physiol. 2015;119(10):1194-201.

48. Siebenmann C, Robach P, Lundby C. Regulation of blood volume in lowlanders exposed to high altitude. J Appl Physiol. 2017;123(4):957-66.

49. Heinicke K, Prommer N, Cajigal J, et al. Long-term exposure to intermittent hypoxia results in increased hemoglobin mass, reduced plasma volume, and elevated erythropoietin plasma levels in man. Eur J Appl Physiol. 2003;88(6):535-43.

50. Larson-Meyer DE, Woolf K, Burke L. Assessment of nutrient status in athletes and the need for supplementation. Int J Sport Nutr Exerc Metab. 2018;28(2):139-58.
51. Gore CJ, Sharpe K, Garvican-Lewis LA, et al. Altitude training and haemoglobin mass from the optimised carbon monoxide rebreathing method determined by a meta-analysis. Br J Sports Med. 2013;47(Suppl 1):i31-9.

52. Robach P, Siebenmann C, Jacobs RA, et al. The role of haemoglobin mass on $\mathrm{VO}(2)$ max following normobaric 'live high-train low' in endurance-trained athletes. Br J Sports Med. 2012;46(11):822-7.

53. Stray-Gundersen J, Alexander AC, Hochstein A, et al. Failure of red cell volume to increase to altitude exposure in iron deficient runners. Med Sci Sports Exerc. 1992;24:S90.

54. Ryan BJ, Wachsmuth NB, Schmidt WF, et al. AltitudeOmics: rapid hemoglobin mass alterations with early acclimatization to and de-acclimatization from $5260 \mathrm{~m}$ in healthy humans. PLoS One. 2014;9(10):e108788.

55. Garvican-Lewis LA, Vuong VL, Govus AD, et al. Intravenous iron does not augment the hemoglobin mass response to simulated hypoxia. Med Sci Sports Exerc. 2018;50(8):1669-78.

56. Garvican-Lewis LA, Govus AD, Peeling P, et al. Iron supplementation and altitude: decision making using a regression tree. J Sci Med Sport. 2016;15:204-5.

57. Hall R, Peeling P, Nemeth E, et al. Single versus split dose of iron optimizes hemoglobin mass gains at $2106 \mathrm{~m}$ altitude. Med Sci Sports Exerc. 2019;51(4):751-9.

58. Pedlar CR, Brugnara C, Bruinvels G, et al. Iron balance and iron supplementation for the female athlete: a practical approach. Eur J Sport Sci. 2018;18(2):295-305.

59. Pedlar CR, Whyte GP, Burden R, et al. A case study of an irondeficient female Olympic 1500-m runner. Int J Sports Physiol Perform. 2013;8(6):695-8.

60. Govus AD, Garvican-Lewis LA, Abbiss CR, et al. Pre-altitude serum ferritin levels and daily oral iron supplement dose mediate iron parameter and hemoglobin mass responses to altitude exposure. PLoS One. 2015;10(8):e0135120.

61. Macdougall IC. Evolution of iv iron compounds over the last century. J Ren Care. 2009;35(Suppl 2):8-13.

62. Rishi G, Wallace DF, Subramaniam VN. Hepcidin: regulation of the master iron regulator. Biosci Rep. 2015;35(3):e00192.

63. Govus AD, Peeling P, Abbiss CR, et al. Live high, train lowinfluence on resting and post-exercise hepcidin levels. Scand J Med Sci Sports. 2017;27(7):704-13.

64. Peeling P, Sim M, Badenhorst CE, et al. Iron status and the acute post-exercise hepcidin response in athletes. PLoS One. 2014;9(3):e93002.

65. Nemeth E, Tuttle MS, Powelson J, et al. Hepcidin regulates cellular iron efflux by binding to ferroportin and inducing its internalization. Science. 2004;306(5704):2090-3.

66. Moretti D, Goede JS, Zeder C, et al. Oral iron supplements increase hepcidin and decrease iron absorption from daily or twice-daily doses in iron-depleted young women. Blood. 2015;126(17):1981-9.

67. Stoffel NU, Cercamondi CI, Brittenham G, et al. Iron absorption from oral iron supplements given on consecutive versus alternate days and as single morning doses versus twice-daily split dosing in iron-depleted women: two open-label, randomised controlled trials. Lancet Haematol. 2017;4(11):e524-33.

68. Cancelo-Hidalgo MJ, Castelo-Branco C, Palacios S, et al. Tolerability of different oral iron supplements: a systematic review. Curr Med Res Opin. 2013;29(4):291-303.

69. Schaap CC, Hendriks JC, Kortman GA, et al. Diurnal rhythm rather than dietary iron mediates daily hepcidin variations. Clin Chem. 2013;59(3):527-35.

70. Fisher AE, Naughton DP. Iron supplements: the quick fix with long-term consequences. Nutr J. 2004;3:2. 
71. Munoz M, Gomez-Ramirez S, Bhandari S. The safety of available treatment options for iron-deficiency anemia. Expert Opin Drug Saf. 2018;17(2):149-59.

72. Pialoux V, Mounier R, Rock E, et al. Effects of the 'live hightrain low' method on prooxidant/antioxidant balance on elite athletes. Eur J Clin Nutr. 2009;63(6):756-62.

73. Dosek A, Ohno H, Acs Z, et al. High altitude and oxidative stress. Respir Physiol Neurobiol. 2007;158(2-3):128-31.

74. Sies H, Berndt C, Jones DP. Oxidative Stress. Annu Rev Biochem. 2017;86:715-48.

75. Pialoux V, Mounier R, Rock E, et al. Effects of acute hypoxic exposure on prooxidant/antioxidant balance in elite endurance athletes. Int J Sports Med. 2009;30(2):87-93.

76. Wadley AJ, Svendsen IS, Gleeson M. Heightened exerciseinduced oxidative stress at simulated moderate level altitude vs. sea level in trained cyclists. Int J Sport Nutr Exerc Metab. 2017;27(2):97-104.

77. Vasankari TJ, Kujala UM, Rusko H, et al. The effect of endurance exercise at moderate altitude on serum lipid peroxidation and antioxidative functions in humans. Eur J Appl Physiol Occup Physiol. 1997;75(5):396-9.

78. Subudhi AW, Davis SL, Kipp RW, et al. Antioxidant status and oxidative stress in elite alpine ski racers. Int J Sport Nutr Exerc Metab. 2001;11(1):32-41

79. Pialoux V, Brugniaux JV, Rock E, et al. Antioxidant status of elite athletes remains impaired 2 weeks after a simulated altitude training camp. Eur J Nutr. 2010;49(5):285-92.

80. Debevec T, Pialoux V, Saugy J, et al. Prooxidant/antioxidant balance in hypoxia: a cross-over study on normobaric vs. hypobaric "live high-train low". PLoS One. 2015;10(9):e0137957.

81. Goods PS, Dawson B, Landers GJ, et al. Effect of repeat-sprint training in hypoxia on post-exercise interleukin-6 and F2-isoprostanes. Eur J Sport Sci. 2016;16(8):1047-54.

82. Debevec T, Millet GP, Pialoux V. Hypoxia-induced oxidative stress modulation with physical activity. Front Physiol. 2017;8:84.

83. Pialoux V, Mounier R, Brugniaux JV, et al. Thirteen days of "live high-train low" does not affect prooxidant/antioxidant balance in elite swimmers. Eur J Appl Physiol. 2009;106(4):517-24.

84. Lewis NA, Howatson G, Morton K, et al. Alterations in redox homeostasis in the elite endurance athlete. Sports Med. 2015;45(3):379-409.

85. Quindry J, Dumke C, Slivka D, et al. Impact of extreme exercise at high altitude on oxidative stress in humans. J Physiol. 2016;594(18):5093-104.

86. Askew EW. Work at high altitude and oxidative stress: antioxidant nutrients. Toxicology. 2002;180(2):107-19.

87. Irarrazaval S, Allard C, Campodonico J, et al. Oxidative stress in acute hypobaric hypoxia. High Alt Med Biol. 2017;18(2):128-34.

88. Bailey DM, Taudorf S, Berg RM, et al. Increased cerebral output of free radicals during hypoxia: implications for acute mountain sickness? Am J Physiol Regul Integr Comp Physiol. 2009;297(5):R1283-92.

89. Hartmann G, Tschop M, Fischer R, et al. High altitude increases circulating interleukin-6, interleukin-1 receptor antagonist and C-reactive protein. Cytokine. 2000;12(3):246-52.

90. Schippinger G, Fankhauser F, Abuja PM, et al. Competitive and seasonal oxidative stress in elite alpine ski racers. Scand J Med Sci Sports. 2009;19(2):206-12.

91. Niess AM, Fehrenbach E, Strobel G, et al. Evaluation of stress responses to interval training at low and moderate altitudes. Med Sci Sports Exerc. 2003;35(2):263-9.

92. Pyne DV, McDonald WA, Morton DS, et al. Inhibition of interferon, cytokine, and lymphocyte proliferative responses in elite swimmers with altitude exposure. J Interferon Cytokine Res. 2000;20(4):411-8.
93. Walsh NP, Oliver SJ. Exercise, immune function and respiratory infection: an update on the influence of training and environmental stress. Immunol Cell Biol. 2016;94(2):132-9.

94. Simon-Schnass I, Pabst H. Influence of vitamin E on physical performance. Int J Vitam Nutr Res. 1988;58(1):49-54.

95. Bailey DM, Davies B. Acute mountain sickness; prophylactic benefits of antioxidant vitamin supplementation at high altitude. High Alt Med Biol. 2001;2(1):21-9.

96. Schmidt MC, Askew EW, Roberts DE, et al. Oxidative stress in humans training in a cold, moderate altitude environment and their response to a phytochemical antioxidant supplement. Wilderness Environ Med. 2002;13(2):94-105.

97. Subudhi AW, Jacobs KA, Hagobian TA, et al. Antioxidant supplementation does not attenuate oxidative stress at high altitude. Aviat Space Environ Med. 2004;75(10):881-8.

98. Baillie JK, Thompson AA, Irving JB, et al. Oral antioxidant supplementation does not prevent acute mountain sickness: double blind, randomized placebo-controlled trial. QJM. 2009;102(5):341-8.

99. Chao WH, Askew EW, Roberts DE, et al. Oxidative stress in humans during work at moderate altitude. J Nutr. 1999;129(11):2009-12.

100. Powers SK, Duarte J, Kavazis AN, et al. Reactive oxygen species are signalling molecules for skeletal muscle adaptation. Exp Physiol. 2010;95(1):1-9.

101. Pialoux V, Brugniaux JV, Fellmann N, et al. Oxidative stress and HIF-1 alpha modulate hypoxic ventilatory responses after hypoxic training on athletes. Respir Physiol Neurobiol. 2009;167(2):217-20.

102. Merry TL, Ristow M. Do antioxidant supplements interfere with skeletal muscle adaptation to exercise training? J Physiol. 2016;594(18):5135-47.

103. Ristow M, Zarse K, Oberbach A, et al. Antioxidants prevent health-promoting effects of physical exercise in humans. Proc Natl Acad Sci USA. 2009;106(21):8665-70.

104. Margaritelis NV, Theodorou AA, Paschalis V, et al. Adaptations to endurance training depend on exercise-induced oxidative stress: exploiting redox interindividual variability. Acta Physiol (Oxf). 2018. https://doi.org/10.1111/apha.12898.

105. Paulsen G, Cumming KT, Holden G, et al. Vitamin C and E supplementation hampers cellular adaptation to endurance training in humans: a double-blind, randomised, controlled trial. J Physiol. 2014;592(8):1887-901.

106. Koivisto AE, Olsen T, Paur I, Paulsen G, Bastani NE, Garthe I, Raastad T, Matthews J, Blomhoff R, Bøhn SK. Effects of antioxidant-rich foods on altitude-induced oxidative stress and inflammation in elite endurance athletes: a randomized controlled trial. PLoS One. 2019;14(6):e0217895. https://doi.org/10.1371/ journal.pone.0217895.

107. Peeling P, Binnie MJ, Goods PSR, et al. Evidence-based supplements for the enhancement of athletic performance. Int J Sport Nutr Exerc Metab. 2018;28(2):178-87.

108. Shannon OM, McGawley K, Nyback L, et al. "Beet-ing" the mountain: a review of the physiological and performance effects of dietary nitrate supplementation at simulated and terrestrial altitude. Sports Med. 2017;47(11):2155-69.

109. Jones AM. Dietary nitrate supplementation and exercise performance. Sports Med. 2014;44(Suppl 1):S35-45.

110. Kelly J, Vanhatalo A, Bailey SJ, et al. Dietary nitrate supplementation: effects on plasma nitrite and pulmonary $\mathrm{O}_{2}$ uptake dynamics during exercise in hypoxia and normoxia. Am J Physiol Regul Integr Comp Physiol. 2014;307(7):R920-30.

111. Masschelein E, Van Thienen R, Wang X, et al. Dietary nitrate improves muscle but not cerebral oxygenation status during exercise in hypoxia. J Appl Physiol. 2012;113(5):736-45. 
112. Muggeridge DJ, Howe CC, Spendiff O, et al. A single dose of beetroot juice enhances cycling performance in simulated altitude. Med Sci Sports Exerc. 2014;46(1):143-50.

113. Carriker CR, Mermier CM, Van Dusseldorp TA, et al. Effect of acute dietary nitrate consumption on oxygen consumption during submaximal exercise in hypobaric hypoxia. Int J Sport Nutr Exerc Metab. 2016;26(4):315-22.

114. MacLeod KE, Nugent SF, Barr SI, et al. Acute beetroot juice supplementation does not improve cycling performance in normoxia or moderate hypoxia. Int J Sport Nutr Exerc Metab. 2015;25(4):359-66.

115. Arnold JT, Oliver SJ, Lewis-Jones TM, et al. Beetroot juice does not enhance altitude running performance in well-trained athletes. Appl Physiol Nutr Metab. 2015;40(6):590-5.

116. Bourdillon N, Fan JL, Uva B, et al. Effect of oral nitrate supplementation on pulmonary hemodynamics during exercise and time trial performance in normoxia and hypoxia: a randomized controlled trial. Front Physiol. 2015;6:288.

117. Kent GL, Dawson B, McNaughton LR, Cox GR, Burke LM, Peeling P. The effect of beetroot juice supplementation on repeatsprint performance in hypoxia. J Sports Sci. 2019;37(3):339-46. https://doi.org/10.1080/02640414.2018.1504369.

118. Rokkedal-Lausch T, Franch J, Poulsen MK, et al. Chronic highdose beetroot juice supplementation improves time trial performance of well-trained cyclists in normoxia and hypoxia. Nitric Oxide. 2019;85:44-52.

119. Roberts D, Smith DJ. Erythropoietin concentration and arterial haemoglobin saturation with supramaximal exercise. J Sports Sci. 1999;17(6):485-93.

120. Puype J, Ramaekers M, Van Thienen R, et al. No effect of dietary nitrate supplementation on endurance training in hypoxia. Scand J Med Sci Sports. 2015;25(2):234-41.

121. De Smet S, Van Thienen R, Deldicque L, et al. Nitrate intake promotes shift in muscle fiber type composition during sprint interval training in hypoxia. Front Physiol. 2016;7:233.

122. Rossetti GMK, Macdonald JH, Wylie LJ, et al. Dietary nitrate supplementation increases acute mountain sickness severity and sense of effort during hypoxic exercise. J Appl Physiol. 2017;123(4):983-92.

123. Hultman E, Sahlin K. Acid-base balance during exercise. Exerc Sport Sci Rev. 1980;8:41-128.

124. Stellingwerff T, Bovim IM, Whitfield J. Contemporary nutrition interventions to optimize performance in middle-distance runners. Int J Sport Nutr Exerc Metab. 2019;29(2):106-16.

125. Stellingwerff T, Maughan RJ, Burke LM. Nutrition for power sports: middle-distance running, track cycling, rowing, canoeing/kayaking, and swimming. J Sports Sci. 2011;29(Suppl 1):S79-89.

126. Cerretelli P, Samaja M. Acid-base balance at exercise in normoxia and in chronic hypoxia. Revisiting the "lactate paradox". Eur J Appl Physiol. 2003;90(5-6):431-48.

127. Juel C, Lundby C, Sander M, et al. Human skeletal muscle and erythrocyte proteins involved in acid-base homeostasis: adaptations to chronic hypoxia. J Physiol. 2003;548(Pt 2):639-48.

128. Mizuno M, Juel C, Bro-Rasmussen T, et al. Limb skeletal muscle adaptation in athletes after training at altitude. J Appl Physiol. 1990;68(2):496-502.

129. Saltin B, Kim CK, Terrados N, et al. Morphology, enzyme activities and buffer capacity in leg muscles of Kenyan and Scandinavian runners. Scand J Med Sci Sports. 1995;5(4):222-30.

130. Nummela A, Rusko H. Acclimatization to altitude and normoxic training improve 400-m running performance at sea level. J Sports Sci. 2000;18(6):411-9.

131. Kozak-Collins K, Burke ER, Schoene RB. Sodium bicarbonate ingestion does not improve performance in women cyclists. Med Sci Sports Exerc. 1994;26(12):1510-5.
132. Flinn S, Herbert K, Graham K, et al. Differential effect of metabolic alkalosis and hypoxia on high-intensity cycling performance. J Strength Cond Res. 2014;28(10):2852-8.

133. Fernandez-Castanys BF, Fernandez MD, Garcia JA. The effect of sodium citrate intake on anaerobic performance in normoxia and after sudden ascent to a moderate altitude. J Sports Med Phys Fit. 2002;42(2):179-85.

134. Kayser B, Ferretti G, Grassi B, et al. Maximal lactic capacity at altitude: effect of bicarbonate loading. J Appl Physiol. 1993;75(3):1070-4

135. McLellan T, Jacobs I, Lewis W. Acute altitude exposure and altered acid-base states. II. Effects on exercise performance and muscle and blood lactate. Eur J Appl Physiol Occup Physiol. 1988;57(4):445-51.

136. Hausswirth C, Bigard AX, Lepers R, et al. Sodium citrate ingestion and muscle performance in acute hypobaric hypoxia. Eur J Appl Physiol Occup Physiol. 1995;71(4):362-8.

137. Deb SK, Gough LA, Sparks SA, et al. Determinants of curvature constant (W') of the power duration relationship under normoxia and hypoxia: the effect of pre-exercise alkalosis. Eur J Appl Physiol. 2017;117(5):901-12.

138. Edge J, Bishop D, Goodman C. Effects of chronic $\mathrm{NaHCO}_{3}$ ingestion during interval training on changes to muscle buffer capacity, metabolism, and short-term endurance performance. J Appl Physiol. 2006;101(3):918-25.

139. McNaughton L, Thompson T. Acute versus chronic sodium bicarbonates ingestion and anaerobic work and power output. J Sports Med Phys Fit. 2001;41:456-62.

140. McNaughton L, Backx K, Palmer G, et al. Effects of chronic bicarbonate ingestion on the performance of high-intensity work. Eur J Appl Physiol Occup Physiol. 1999;80(4):333-6.

141. Douroudos II, Fatouros IG, Gourgoulis V, et al. Dose-related effects of prolonged $\mathrm{NaHCO}_{3}$ ingestion during high-intensity exercise. Med Sci Sports Exerc. 2006;38(10):1746-53.

142. Sims ST, Rehrer NJ, Bell ML, et al. Preexercise sodium loading aids fluid balance and endurance for women exercising in the heat. J Appl Physiol. 2007;103(2):534-41.

143. Sims ST, van Vliet L, Cotter JD, et al. Sodium loading aids fluid balance and reduces physiological strain of trained men exercising in the heat. Med Sci Sports Exerc. 2007;39(1):123-30.

144. Carr AJ, Slater GJ, Gore CJ, et al. Effect of sodium bicarbonate on $\left[\mathrm{HCO}_{3}{ }^{-}\right], \mathrm{pH}$, and gastrointestinal symptoms. Int J Sport Nutr Exerc Metab. 2011;21(3):189-94.

145. Price MJ, Simons $C$. The effect of sodium bicarbonate ingestion on high-intensity intermittent running and subsequent performance. J Strength Cond Res. 2010;24(7):1834-42.

146. Saunders B, Sale C, Harris RC, et al. Sodium bicarbonate and high-intensity-cycling capacity: variability in responses. Int J Sports Physiol Perform. 2014;9(4):627-32.

147. Hoffman JR, Ratamess NA, Faigenbaum AD, et al. Short-duration beta-alanine supplementation increases training volume and reduces subjective feelings of fatigue in college football players. Nutr Res. 2008;28(1):31-5.

148. Smith AE, Moon JR, Kendall KL, et al. The effects of betaalanine supplementation and high-intensity interval training on neuromuscular fatigue and muscle function. Eur J Appl Physiol. 2009;105(3):357-63.

149. Saunders B, Sale C, Harris RC, et al. Effect of sodium bicarbonate and beta-alanine on repeated sprints during intermittent exercise performed in hypoxia. Int J Sport Nutr Exerc Metab. 2014;24(2):196-205.

150. Burgunder JM, Varriale A, Lauterburg BH. Effect of $N$-acetylcysteine on plasma cysteine and glutathione following paracetamol administration. Eur J Clin Pharmacol. 1989;36(2):127-31. 
151. Slattery KM, Dascombe B, Wallace LK, et al. Effect of $N$-acetylcysteine on cycling performance after intensified training. Med Sci Sports Exerc. 2014;46(6):1114-23.

152. McKenna MJ, Medved I, Goodman CA, et al. N-acetylcysteine attenuates the decline in muscle $\mathrm{Na}+\mathrm{K}+$-pump activity and delays fatigue during prolonged exercise in humans. J Physiol. 2006;576(Pt 1):279-88.

153. Droge W, Breitkreutz R. Glutathione and immune function. Proc Nutr Soc. 2000;59(4):595-600.

154. Zembron-Lacny A, Slowinska-Lisowska M, Szygula Z, et al. Modulatory effect of $\mathrm{N}$-acetylcysteine on pro-antioxidant status and haematological response in healthy men. J Physiol Biochem. 2010;66(1):15-21.

155. Hildebrandt W, Alexander S, Bartsch P, et al. Effect of $N$-acetylcysteine on the hypoxic ventilatory response and erythropoietin production: linkage between plasma thiol redox state and $\mathrm{O}(2)$ chemosensitivity. Blood. 2002;99(5):1552-5.

156. Freudenthaler SM, Schreeb KH, Wiese A, et al. Influence of controlled hypoxia and radical scavenging agents on erythropoietin and malondialdehyde concentrations in humans. Acta Physiol Scand. 2002;174(3):231-5.

157. Kleinveld HA, Demacker PN, Stalenhoef AF. Failure of $N$-acetylcysteine to reduce low-density lipoprotein oxidizability in healthy subjects. Eur J Clin Pharmacol. 1992;43(6):639-42.

158. Mishra KP, Ganju L. Influence of high altitude exposure on the immune system: a review. Immunol Investig. 2010;39(3):219-34.

159. Tsai TY, Wang SH, Lee YK, et al. Ginkgo biloba extract for prevention of acute mountain sickness: a systematic review and meta-analysis of randomised controlled trials. BMJ Open. 2018;8(8):e022005.

160. Gertsch JH, Basnyat B, Johnson EW, et al. Randomised, double blind, placebo controlled comparison of Ginkgo biloba and acetazolamide for prevention of acute mountain sickness among Himalayan trekkers: the prevention of high altitude illness trial (PHAIT). BMJ. 2004;328(7443):797.

161. Bailey DM, Davies B. Physiological implications of altitude training for endurance performance at sea level: a review. Br J Sports Med. 1997;31(3):183-90.

162. Moraga FA, Flores A, Serra J, et al. Ginkgo biloba decreases acute mountain sickness in people ascending to high altitude at Ollague (3696 m) in northern Chile. Wilderness Environ Med. 2007;18(4):251-7.

163. Gassmann M, Muckenthaler MU. Adaptation of iron requirement to hypoxic conditions at high altitude. J Appl Physiol. 2015;119(12):1432-40.

164. Sim M, Dawson B, Landers G, et al. Iron regulation in athletes: exploring the menstrual cycle and effects of different exercise modalities on hepcidin production. Int J Sport Nutr Exerc Metab. 2014;24(2):177-87.

165. Telford RD, Sly GJ, Hahn AG, et al. Footstrike is the major cause of hemolysis during running. J Appl Physiol. 2003;94(1):38-42.

166. Hurrell R, Egli I. Iron bioavailability and dietary reference values. Am J Clin Nutr. 2010;91(5):1461S-7S. 